[This is a pre-print version of an article to appear in Language Variation and Change.

Please consult the final version if citing.]

\title{
Scalar effects of social networks on language variation
}

\author{
Devyani Sharma \\ Queen Mary, University of London
}

\begin{abstract}
The role of social networks in language variation has been studied using a wide range of metrics. This study critically examines the effect of different dimensions of networks on different aspects of language variation. Three dimensions of personal network (ethnicity, nationality, diversity) are evaluated in relation to three levels of language structure (phonetic form, accent range, language choice) over three generations of British Asians. The results indicate a scaling of network influences. The two metrics relating to qualities of an individual's ties are more historically and culturally specific, whereas the network metric that relates to the structure of an individual's social world appears to exert a more general effect on accent repertoires across generations. This two-tier typology-network qualities (more culturally contingent) and network structures (more general)-facilitates an integrated understanding of previous studies and a more structured methodology for studying the effect of social networks on language.
\end{abstract}

\section{INTRODUCTION}

Social networks have long been recognized as central to how people speak. Some studies have identified powerful general network mechanisms in language change (e.g., Milroy and Milroy, 1978), while others have focused on more community-specific dynamics (e.g., Gal, 1978). A broad picture of how and why language is influenced by social networks thus tends to be complicated by the difficulty of comparing across studies and the tendency to select network measures relevant to the community in question.

The present study broadens the lens to better understand network dynamics. It contrasts three different aspects of social network structure - grounded in separate hypotheses - and explores their impact on three different levels of language variation: phonetic form, style range, and language choice. The data examined come from multiple generations of a British Asian community in the United Kingdom, and so additionally permit a consideration of how network effects behave over time in a community undergoing social change. The research design thus incorporates three dimensions:

- A network scale (3 levels of network information)

- A structural scale (3 levels of language structure)

- A temporal scale (3 degrees of community depth)

The study finds that some social network influences are very localized-influencing a particular speech feature for a particular subgroup at a particular historical phase of the community. This is especially true for qualities present within an individual's personal networks (e.g., proportion of a 
certain ethnicity in the network). By contrast, a structural network measure, which concerns the geometry of the network itself, is shown to exert a more stable, wide-ranging influence. Strength of ties have been argued in the literature to be one such general influence on language variation. In this community, another structural property of networks, the diversity of a person's network, is shown to correspond closely to how diverse their speech repertoire is, regardless of cross-cutting factors such as gender, age, or historical phase.

The article thus distinguishes between two ways in which social networks influence language: their role as the basic structure of our social worlds, potentially exerting more general influence in the data, and their role as a conduit for culturally and historically specific social qualities to affect language. This exploratory two-way typology may help to organize some of the multidimensionality of social networks, inform analysts' choices of metrics, and "create a more unified social-network research methodology" in the study of language variation (de Bot \& Stoessel, 2002:5).

The article first outlines a few concepts from social network theory, used in the next section to structure a brief review of sociolinguistic network studies to date. The following section provides details of the community, the research design, and the various indexes used. The analysis that follows reveals temporal and structural scaling in network effects on language across generations in the community. The discussion focuses on why some network components exert more localized effects in the community than others do, with implications for wider network modeling in sociolinguistics.

\section{PROPERTIES OF NETWORKS}

The Milroys' seminal study of Belfast (Milroy, 1987; Milroy \& Milroy, 1978) not only transformed sociolinguistics, it shifted a long-standing focus on strong network ties in the wider study of language change ("the limit of spread is sure to be along some line of weakness in the network of oral communication" [Bloomfield, 1933:328]). While affirming the conservative effect of strong ties, the Belfast study showcased a community in which the central role of weak ties in diffusion was apparent. Milroy (1987) investigated many dimensions of social networks in the community, but the most influential has been the factor of strength of ties, as measured through density (how interlinked nodes are) and multiplexity (the number of social connections between two nodes). Many sociolinguistics textbooks still cite only these two measures, even though many studies since have employed other metrics, reviewed in the next section.

In her closing comments, Milroy (1987) observed that "a convincing case could be made... for using several different kinds of indicator," noting that although social networks may have "a very general and possibly universal applicability . . the indicators which may be said to reflect the underlying structure of personal relationships will vary in accordance with the investigator's perception of the most relevant and easily measurable categories" (216). Her comments highlight a tension between claims of general, even universal, network effects on language and their more community-specific embedding. This tension has impeded systematic comparison of network effects across studies, but it may be resolvable with a more reflexive and comparative approach in methodology (how analytic choices affect outcomes) and in theory (why some network traits may have a more consistent effect on language than others).

The present study takes up these open questions: Should we use "several different kinds of indicator" to fully understand network dynamics in a speech community? How localized, general, or even universal, is the effect of such indicators on language use?

To begin to answer these questions, it is useful to step back from the historical focus on strength of ties, while in no way questioning its centrality in language variation, and instead begin with a broader picture of the many loci in a network we could in principle study. One important contrast is whether we choose to examine personal networks or whole networks (sometimes 
termed ego network analysis and total network analysis; Degenne \& Forsé [1999:13]; Wetherell [1998:127]).

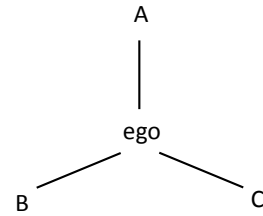

(a) ego star

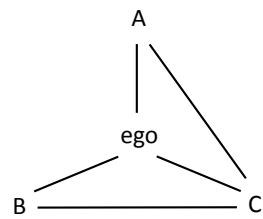

(b) ego zone

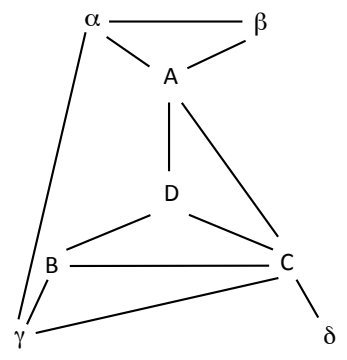

(c) second order zones and whole networks

Figure 1: Stars, zones, and networks (modified from Degenne and Forsé 1999: 26)

Figure 1 illustrates these levels of network information we might use. An ego star (Figure 1a) represents a set of relations between a given actor (ego) and others (alters). In ego star data, only properties of individual stars, or personal networks, can be studied, such as the multiplexity of each ego-alter dyad, the proportion of a given qualitative trait in each star (e.g., ethnicity, class, sexuality), or the total number of alters in each star. This provides some network information per individual while still permitting stratified sampling, as participants need not be linked in a single network. For these reasons, ego star data are common in sociolinguistic research.

Figure $1 \mathrm{~b}$ describes a closely related type of information, namely, the ego zone. This expands the information known about an ego to include facts about alter-alter ties, but still excludes details about how this cluster is positioned in the wider network. In sociolinguistics, as reviewed next, studies that extend to this level have tended to focus on density (the number of mutual ties among alters of a given ego). The present study introduces and examines a different ego zone measure, network diversity.

Finally, we can add in the zones of alters, as in Figure 1c, to create second-order ego zones (cf. Milroy, 1987:46-47), moving toward increasingly complex sociograms and ultimately whole networks. Whole networks permit an examination of more complex structural components such as clusters, chains, cohesion, centrality, structural holes, and other formations. These are potentially very powerful for understanding language variation but, for reasons noted in the next section, current sociolinguistic methods are somewhat limited in their ability to conduct whole network analysis.

In addition to these levels of network data, there exists a contrast in the type of information we might choose to examine. As social networks represent the structural arrangement of people as well as the interactions transacted between them, we can distinguish between structural and content (or quality) components at any level. Structural components represent the actual geometry or arrangement of ties, such as density. Content components involve the qualities present within these ties, for instance relating to interaction, such as multiplexity, reciprocity, and transactions (Bergs, 2005; Milardo, 1988), or to attributes, such as ethnicity of individuals, the focus of this study. Using ego star and ego zone data, the present study explores the possibility that network structures and network qualities influence language variation in different ways.

\section{NETWORK MEASURES IN SOCIOLINGUISTICS}

If we view the history of social network analysis in sociolinguistics through Figure 1, we see that some studies have examined whole networks and structural components, but more have explored 
ego network data and content or quality components. I offer a brief review here to motivate the comparative approach taken in the present study.

True whole network analysis ideally compares multiple whole networks. For reasons of feasibility and sampling, this is rare in sociolinguistics. In Milroy (1987), multiplexity and density of neighbourhood networks were inferred from etically derived indexes for clustered individuals in different local communities. Other early studies used detailed sociograms of single networks and so could similarly examine various structural network components. Thus, in their well-known analyses of vernacular language, Labov (1972) used details of network location of gang members, Eckert (2000) used details of centrality and asymmetry of jocks and burnouts, and Cheshire (1982) used adolescents' core and peripheral engagement in social networks.

Community of Practice studies have tended to retain this interest in structural network positions (e.g., Moore, 2006). Some studies have found creative solutions to the challenge of gathering whole network data, using computational modeling (Fagyal, Swarup, Escobar, Gasser \& Lakkaraju 2010), Internet Relay Chat data (Paolillo 1999), and historical records (Bergs, 2005; Deumert, 2004), with the last of these also encouraging sensitivity to biographical or political specifics in network coding (see also Lippi-Green [1989], Matsumoto [2010], and Smith [2002] on the importance of an ethnographic understanding of network clusters). Dodsworth and Benton (2017) offered a major advance in whole network analysis in sociolinguistics, devising sociologically sophisticated and replicable new measures for large-scale analysis of the effect of structural components such as cohesion.

Ego network analysis is more common in sociolinguistics for several reasons. Whole network analysis can require a comparison of several whole networks, which is often unfeasible given the demands of sociolinguistic data collection. Ego network data are also more compatible with stratified sampling of participants, often needed for other reasons in variationist research. At the level of analysis too, ego network metrics can be easier to integrate alongside other social factors in multivariate statistics. Many early studies therefore used ego star information gleaned from individual self-reports, for example Gal's (1978) measure of peasantness of individual networks, Dubois and Horvath's (1998) measure of openness of individual networks, and Bortoni-Ricardo's (1985) individual integration and urbanization network indexes, finely tuned to the situation of rural migrants in a Brazilian city.

Ethnicity, the main focus of the present study, is a particularly well-researched ego star quality (e.g., Cheshire, Fox, Kerswill, \& Torgersen, 2008; Hoffman \& Walker, 2010; Li Wei, 1994; Matsumoto, 2010; Meyerhoff \& Schleef, 2012; Newman, 2010; Sharma \& Sankaran, 2011; Stoessel, 2002; Wassink, 2016; Wong, 2010, among others). A common focus in the study of ethnicity is the proportion of a given ethnicity in each person's network, particularly in relation to their own ethnicity (ethnic homophily; see Wassink, 2016). It has also been common to establish values for these indexes by eliciting a fixed number of reported ties (e.g., Bortoni-Ricardo, 1985; Lanza \& Svendsen, 2007; Li Wei, 1994; Matsumoto, 2010); in a few exceptions (e.g., Wassink 2016; Wong, 2010), participants could determine the number of ties they reported.

Some of these common methodological choices - a focus on the ethnic composition of individual networks, eliciting a fixed number of ties, a focus on density - are critically evaluated in the present study through a comparison of theoretically motivated alternatives. The comparison of metrics is organized around the distinction mentioned earlier: network qualities and network structures.

Network qualities: Correlations between the ethnicity of an individual's network and their language use tend to be interpreted as acts of ethnic identification. But we know that people are also sensitive to the speech of their interlocutors. In principle, then, it could be the presence of a particular language or accent type in their network, not simply a certain ethnicity, that is the driving factor in such cases (see Hulsen, de Bot, \& Weltens [2002] and Stoessel [2002] for use of this alternative). In some cases, analysts may even be using ethnicity as a proxy for interlocutor speech. It is therefore useful to disentangle these two components, to establish whether they 
represent distinct social processes. The present study compares the effect on language of these two network qualities: ethnic composition of an ego star and accent/language composition of an ego star.

Network structures: Another common practice worthy of critical reflection is the elicitation of a fixed number of named ties, for example, five closest friends or 10 active ties. While this helps to normalize data for comparison, it can obscure other structural information. If a person's network is large, important ties or groupings may be left out, and if small, unimportant ties may be included. In the present data, ethnographic observation quickly revealed markedly different sizes of personal networks, with very different subgroupings or social worlds in people's daily lives. The study therefore examines the diversity of ego zone subgroupings as an additional factor. This new structural measure differs from density, multiplexity, and openness measures in ways clarified in Data and Methods. The analysis compares the effect of this structural metric to those of the two quality metrics.

The study thus aims not to critique previous approaches but to expand and organize the tools we use for network analysis, encouraging a more comparative and reflexive approach.

\section{DATA AND METHODS}

\section{Community and participants}

The data for this study were collected in Southall, a suburban district in the West London borough of Ealing and the historic heart of the British Punjabi community. The area has attracted South Asians (the largest ethnic minority in the UK) since shortly after World War II, when postwar labor shortages led to policies encouraging migration from former British colonies. The Asian population in the UK grew substantially until 1971, after which a series of immigration acts began to limit numbers, though migration has continued to the present day. Today the South Asian population of Southall is well over $70 \%$ and the overall ethnic minority population exceeds $85 \%$. The South Asian population includes Asia-born first-generation (Gen 1) and British-born second- and third-generation (Gen 2 and Gen 3) residents. Members of the Gen 1 group were born in South Asia and migrated to the UK in adulthood; this group is continually renewed through ongoing migration. Due to their continuous arrival, the Gen 2 group has a very diverse age range. Older Gen 2 people, the first to be born in Britain, are now in their 50s, even 60s. Children of more recent migrants are younger, but also technically Gen 2.

Significant changes in race relations over the last half century have meant very different lived experiences for these older and younger Gen 2 individuals. Between the 1950s and the 1970s, the proportion of South Asians in Southall grew to 30\% - still a minority but a large and highly visible one that became the target of severe racial tension (CARF, 1981:43; Oates, 2002:107). Racially motivated violence was commonplace in schools and on the streets and was formative for older Gen 2 participants, all of whom repeatedly alluded to them in their interviews. Racial tensions were markedly reduced from the 1990s onward, accompanying a shift in demographics such that the Commonwealth heritage population became the majority group (Meads, 1983; Oates, 2002:107). Southall schools became very multiracial, with the proportion of minority ethnic origin students in Ealing schools now ranging from $40 \%$ to $99 \%$ (Ealing JSNA, 2010:18). Younger Gen 2 residents grew up in a climate in which wider British society accepted an increasingly visible, legitimated, even celebrated British Asian culture (Herbert, 2009), and they rarely volunteer narratives of racial tension. These social conditions have led to strikingly different accents and repertoires across generations, examined here in relation to network factors.

Fieldwork was conducted over 9 months by two fieldworkers, the author and another fieldworker who spoke a similar variety of educated Indian English. Data of three broad types were collected: sociolinguistic interviews, social background questionnaires (on network, language use, and cultural practices), and self-recordings. The first two data types were collected 
from a stratified sample (including some small family network clusters of 4-5 relatives) of 75 individuals, mostly through two recorded sessions each. The third type, self-recordings, were collected from a subset of 10 participants. Collecting self-recorded speech repertoires is challenging and it would have been entirely unfeasible to collect a large sample. To permit a degree of generalization, the fieldworkers aimed to collect self-recordings from two participants per major demographic group (e.g., older Gen 2 men). Participants were given Zoom H2 recorders with Sony lavalier microphones for 2 weeks and instructed to record themselves for at least 30 minutes in several different speaking contexts, ideally with different types of interlocutors, focusing in particular on such contrasts as home/work contexts and Asian/nonAsian interlocutors. The repertoires provided varied considerably in terms of number and contexts of recording, and so comparison is kept as simple and transparent as possible in what follows, supported where possible with ethnographic field observation.

The present study relies on interview recordings and questionnaire details from 42 of the 75 participants for whom data were fully processed (18 gender-balanced Gen 1 participants; 24 gender-balanced Gen 2 participants), and self-recorded repertoires from nine individuals. ${ }^{1}$ In both generation groups, participants can be further divided into older (age 35-55) and younger (age 18-34). For Gen 2, this division corresponds to whether individuals grew up during the earlier or later historical phase.

\section{Research design}

The study looks at the influence of three different dimensions of personal network information on language use. These are ethnicity of friendship network (i.e., South Asianness), nationality of friendship network (i.e., Indianness, which for the present data is a direct index of Indian English accent and bilingual dominance in Indian languages), and network diversity (i.e., groupings of alters in the ego zone). The first two measures contrast two network qualities discussed earlier. Is it the ethnicity of alters that influences an ego, or more narrowly the specifics of those alters' speech? The third measure is a new structural network metric designed to target a fundamental facet of people's lives, namely how many different social worlds they participate in.

Just as analyzing only one dimension of social networks may miss the larger picture, analyzing just one linguistic form may do the same. So, the analysis considers the impact of social networks on three distinct levels of language variation: use of Asian postalveolar /t/ (micro level), English accent repertoire across contexts (meso level), and active use of Punjabi (macro level).

Finally, these network and language variables are examined across three generational groups in the community. Table 1 summarizes the multiple dimensions of analysis, each described in detail next.

Table 1: Network measures, language practices, and social groups to be studied

\begin{tabular}{lll}
\hline \hline Network measures & Language practices & Generational groups \\
\hline Ethnic Asianness (quality) & Segmental: Use of $/ \mathrm{t} /$ & First generation \\
Cultural/linguistic Indianness (quality) & Style: Accent repertoire & Older 2 ${ }^{\text {nd }}$ generation \\
Diversity of social worlds (structure) & Language: Use of Punjabi & Younger 2 ${ }^{\text {nd }}$ generation \\
\hline \hline
\end{tabular}

\section{Three measures of network structure}

Milroy (1987:141) acknowledged the methodological challenge of obtaining complete personal network information, noting that "[social network] formulae require a quantitative statement of the size of a total personal network which very few researchers are in a position to provide." In the present study, an estimate of the size, structure, and selected qualities of individual ego zones were targeted during data collection. Participants were not limited to a specific number of ties, 
but rather asked to describe the main groups of people they interacted with on a regular basis, providing further details of each alter, including ethnicity, background, accent, frequency of interaction, domains of interaction, shared ties, and a relative closeness ranking.

The first network measure-Asianness of network - is the proportion of ethnically South Asian close nonkin ties reported by each individual. Family members are excluded, as family often constitutes a large proportion of individuals' networks in this community and so considerably inflates levels of network Asianness. Kin ties do not reflect voluntary sociality as directly as friendships do and so excluding these permits a focus on ties developed and maintained more out of personal choice (Li, 1994:121).

The second network measure-Indianness of network - is the proportion of nonkin ties who were born and raised in India, including alters who are either adult migrants to the UK from India or who live in India. Both by implication speak an Indian variety of English and, in the present data, speak Punjabi as their first language. This index is a subset of the previous index, as it taps more narrowly into the accent, dominant language, and nationality of Asian alters. Especially for Gen 2 it indirectly reflects the degree to which active transnational ties are cultivated and maintained. $^{2}$

The third network measure is a new metric in sociolinguistics: diversity of network. This measure was briefly introduced in Sharma (2011) and is evaluated more fully here in comparison to the two other measures.

As noted, fieldwork revealed sometimes dramatic differences in the size and diversity of individuals' social worlds within and outside the community. An initial analysis used a simple measure of network strength (percentage of weak ties), but this showed no significant effect on any language variables for any subgroups in the community. This appeared to be because the measure only offers an aggregated indication of tie strength, with no indication of how many separate worlds or communities of practice those ties are based in. For example, Anwar, a man who operates across many different social worlds in his daily life, had $56.8 \%$ weak ties, whereas another man, Satpal, has a more limited social world composed of a couple of work colleagues and immediate family, but his proportion of weak ties is similar $(57.1 \%)$.

The Diversity Index used here allows us to retain more of this detail. Diversity indexes have been used widely in other disciplines to measure how diverse the grouping of individuals in a system is, for example, species diversity in biology (Simpson, 1949) and demographic heterogeneity in sociology (Blau, 1977). For example, a given country may have two primary religions with $90 \%$ and $10 \%$ of adherents, respectively, in the population; this would give rise to a lower diversity index than a country with two primary religions distributed evenly in the population, which in turn would have a lower diversity index than a country with four primary religions distributed evenly in the population.

In the present work, I adapt this so that the overall system in question is the social network of an individual, and the subgroupings (religions or species in the preceding examples) are distinct domains of regular interaction. In their social network questionnaire session, each participant listed all of their primary alters in relation to self-described subgroups, for example, family, old school friends, immediate office colleagues, acquaintances at a volunteer site, college friends. The Diversity Index reflects how diverse the distribution of ties in the network is across different groups - that is, how many different social worlds a person's network is composed of and how balanced they are in terms of relative size.

$$
\text { Diversity Index: } \quad D=1-\sum_{i=1}^{n} p_{i}^{2}
$$

In formula (1), $p_{i}$ is the probability that, within a single individual's network, any given alter belongs to any given subgroup $i$ (e.g., work colleagues, close family), and $n$ is the total number of subgroups (Blau, 1977; Degenne \& Forsé, 1999:195). The more subgroups in a network, and the 
more even the distribution of individuals across them, the higher the index value. A higher value (closer to 1) indicates a higher level of diversity, in other words, a lower probability, or predictability, of an alter being in any particular subgroup. By contrast, a lower value (in the direction of 0 ) indicates lower levels of diversity, deriving from either a limited number of subgroups in that person's network or alters being more heavily bunched in just one or two subgroups, for example a person whose main interactions are with their immediate family. Subgroups were treated as distinct if they had no more than one overlapping member. In this use of the Diversity Index, values below .5 are very unlikely because even individuals with relatively small networks will have a minimum of two or three separate subgroups.

Figure 2 shows three such hypothetical networks to illustrate how differences in individuals' social worlds may correspond to higher or lower Diversity Indexes. The second sample network in Figure 2 illustrates an individual who might report regular interaction with just three groups: (a) close family, (b) college friends, and (c) a set of work colleagues, with membership sizes of 4 , 5 , and 3 , respectively. According to (1), $p$ is the probability that an individual is in a given group, so $p(\mathrm{a})=4 / 12, p(\mathrm{~b})=5 / 12$, and $p(\mathrm{c})=3 / 12$. The sum of the squared probabilities is subtracted from 1 . The Diversity Index for this person is therefore .653. The two other sample networks show how different distributions account for different Diversity Index values.

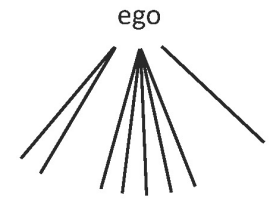

Diversity Index: .531

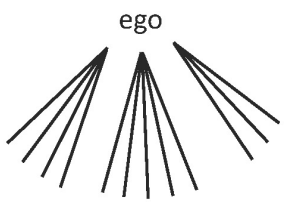

Diversity Index: .653

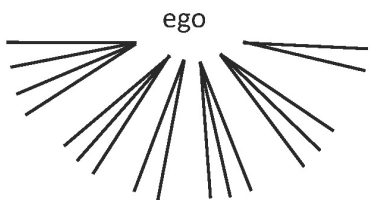

Diversity Index: .824

Figure 2: Sample Diversity Index measures

The index thus incorporates some density information, as subgroupings represent alter-alter ties. It also incorporates some multiplexity information as highly overlapping groups count as single subgroups. However, crucially, it keeps track of the number and relative size of subgroups, adding details of the diversity of social worlds in a person's daily life. As with all network measures, it only attends to certain information and so is not a comprehensive measure. A qualitative detail that could be incorporated in future work, for example, is the status of alters or subgroups as in-group or out-group, that is, a dimension of network openness (cf. Dubois \& Horvath, 1998). Finally, as with many other measures, the new metric relies on complex coding that, however objectively pursued, includes an element of subjective judgment, a critique that Dodsworth and Benton (2017) raise for most structural network measures in sociolinguistics.

\section{Three measures of language use}

The study examines more than one level of language variation to better understand the reach of different network traits within language use. The three aspects of language use examined are postalveolar /t/, accent repertoire, and Punjabi use, representing phonetic choice, style choice, and language choice. Prior analyses of this community (Sharma, 2011; Sharma \& Sankaran, 2011) have examined some aspects of these features individually. In the present study, they are assessed together in relation to the different network factors outlined.

Postalveolar articulation of $/ \mathrm{t} /$, a feature that derives from retroflex consonants in Indic languages, is now a widely recognized feature of British Asian English (Alam, 2007 Alam \& Stuart-Smith, 2014; Heselwood \& McChrystal, 2000; Kirkham, 2011; Lambert, Alam, \& StuartSmith, 2007; Sharma \& Sankaran, 2011). A total of 9350 tokens from interview recordings were subjected to auditory analysis and all variants heard with a realization outside the range of standard British alveolar /t/ (i.e., retroflex as well as retracted forms) were coded as postalveolar. 
Three noncluster positions were coded (syllable-initial, word-medial, and word-final), but they are grouped here. ${ }^{3}$

Accent repertoire, based on the nine sets of self-recordings, is a composite picture of an individual's overall style variation across settings, as seen in their use of four variablespostalveolar /t/, monophthongal /e/, monophthongal /o/, and light coda /1/. The South Asian variants coded for these are [t], [e], [o], [1], in contrast to the British variants [t]/[?], [er], [əv], [t]. These were coded auditorily across as many contexts as were recorded by the individual. At the start of the analysis, repertoires are reduced to a single accent range numerical value to allow an initial comparison to other factors. This is calculated for each individual by first establishing their mean rate of use of each of the four variables per situation, then deriving an overall mean per setting using those four percentage values (due to uneven denominators), and finally subtracting the lowest from the highest derived mean value. Later in the analysis, this extrapolated value is critiqued as somewhat too reductive and accent repertoires are explored in full detail.

The third language feature is use of Punjabi in an individual's daily life. Information was collected on bilingual language use from all participants using a 15-category scale of interlocutor type. The scale was determined through general ethnographic identification of locally relevant categories, for example grandparents, potential for distinct language practices with each parent, and interactions with "aunties," in the Asian sense of relatives as well as acquaintances of the parents' generation. (Contact in commercial settings such as shops was too dependent on the location, type, and ethnic composition to be reliably reported.) These types of observations led to the 15 categories being based around interlocutor and speech task (Gal, 1978) rather than simply domains of interaction (Blom \& Gumperz, 1972). The categories used were: grandparents, grandparents' generation, aunties, mother, father, siblings, spouse, early life (home language before age 5), friends, children, work, counting, writing, university, grandchildren. For each category, individuals were asked to estimate their proportion of Punjabi use as a percentage, and a continuous index $(0 \%-100 \%)$ was derived based on the average of responses of all filled cells. Self-reports risk over- or under-reporting, and this was mitigated through careful clarification with participants, ethnographic observation of participants over 9 months, and verification against 38 self-recordings from participants. Nevertheless, the index is best thought of as a relative index, to compare Punjabi use across individuals, rather than an absolute measure of exact time spent using Punjabi in daily life.

\section{RESULTS}

As the analysis comprises a number of subanalyses, this section starts with an overview of the data followed by individual results for each of the three network traits. These are then pulled together for a wider discussion in the section that follows.

\section{General overview}

The raw data across all 42 participants provides an initial picture of networks and language practices in this community. Figures 3 and 4 provide descriptive statistics for two language practices and two social network measures, respectively. Accent repertoire and network diversity are examined in most detail in relation to each other, for just the nine individuals for whom repertoires exist, so these two traits are omitted from these initial figures.

Figure 3 shows a predictable decline in the use of both postalveolar/t/ and Punjabi in the community, but there is no sharp drop-off in their use between the first and second generations, as is often seen in heritage language communities. The Southall community is well known in London and even in India for its distinctively Asian style of British English and for its maintenance of Punjabi, making it a useful case for testing the interplay of language and network over a longer period of time. 


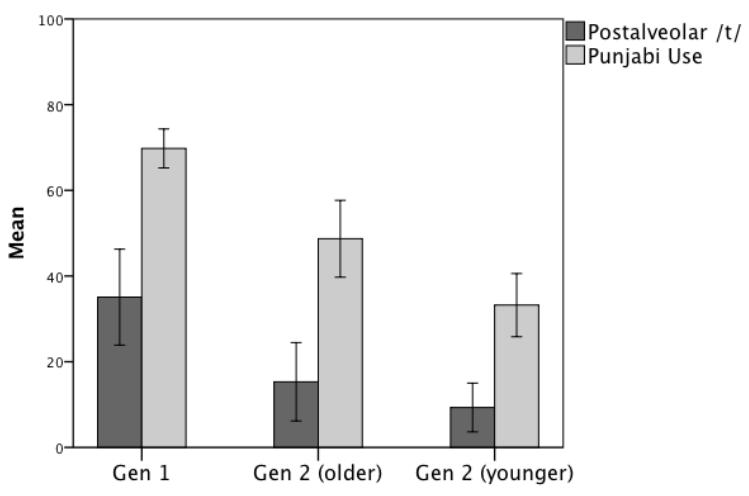

Figure 3: Language practices (use of postalveolar/t/; use of Punjabi) across generations

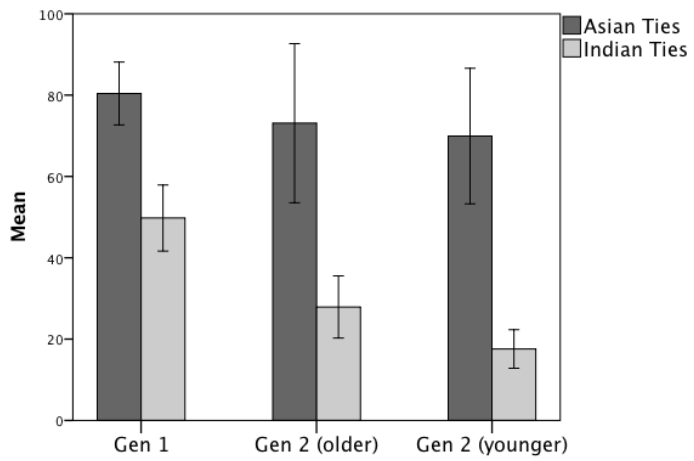

Figure 4: Network properties (Asianness; Indianness of non-kin ties) across generations

Figure 4 shows a contrast that is also typical of this community, namely a maintenance of ethnically Asian networks over time, but an increasing proportion of British Asians within these ties over time, that is, diminishing transnational ties to India. Again, this makes the Southall community particularly well suited for teasing apart the effect of pure ethnicity as opposed to the nationality or accent of alters. ${ }^{4}$

We can now start to explore relationships between social networks and language practices.

The quantitative analyses presented in this article rely almost entirely on nonparametric correlation coefficients. Aside from an initial parametric analysis of a normally distributed subsample of all the data, the remaining analyses separate the data into social subsets, for example by gender and age, and these smaller samples are characterized by mixed normality, presence of 1 to 2 outliers, and uncertain causal directionality, all of which favor use of Spearman's rank correlation coefficient. Multivariate analysis is unfeasible as two of the language traits only include one measure per individual, and one of these is only reported for nine individuals. The later discussion returns to the challenge of ascribing causality in such data.

Table 2 reports a simple correlation matrix across all three network and all three language features, to check for initial patterns in the data. ${ }^{5}$ Table 2 only includes the nine individuals for whom accent range information is available, as these are the only individuals for whom all six measures exist. This small subsample indicates a correspondence between network diversity and repertoire range and also between Indianness of network and Punjabi use. It indicates a lack of correlation in other areas. 
Table 2: Pearson correlation matrix across three network and three language variables

\begin{tabular}{|c|c|c|c|c|c|c|c|}
\hline & & \multicolumn{3}{|c|}{ NETWORK } & \multicolumn{3}{|c|}{ LANGUAGE } \\
\hline & & Asianness & Indianness & Diversity & $\begin{array}{c}\text { Postalveolar } \\
\text { /t/ }\end{array}$ & $\begin{array}{c}\text { Punjabi } \\
\text { use }\end{array}$ & $\begin{array}{c}\text { Repertoire } \\
\text { range }\end{array}$ \\
\hline \multirow{3}{*}{ 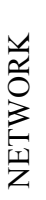 } & Asianness & 1 & & & & & \\
\hline & Indianness & .214 & 1 & & & & \\
\hline & Diversity & .292 & .220 & 1 & & & \\
\hline \multirow{3}{*}{ 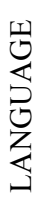 } & Postalveolar/t/ & .313 & .229 & -.133 & 1 & & \\
\hline & Punjabi use & -.258 & $.736 *$ & -.155 & .400 & 1 & \\
\hline & Repertoire range & .156 & .556 & $.667 *$ & .171 & .140 & 1 \\
\hline
\end{tabular}

In the analysis that follows, the first two network qualities are examined in relation to the full set of 42 speakers, and the final, structural network trait is examined specifically in relation to the nine individual repertoires. These further analyses confirm the two initial correlations in Table 2 and identify further patterns in the data, particularly intersections of network with gender, age, and community (generational) time depth.

\section{Network trait 1: Asianness of network}

Across all three demographic groups, how Asian (simple ethnic composition) a person's friendship network is showed no significant correlation with their use of Punjabi, so these results are not reported on further.

By contrast, Table 3 shows that how Asian a person's network is does correlate with their degree of use of postalveolar/t/ for some groups. The correlation is significant overall for Gen 2, but not for Gen 1. This is likely due to high network Asianness and high postalveolar $/ \mathrm{t} / \mathrm{use}$ across the board in Gen 1. Within Gen 2, the breakdown by age and by gender in Table 3 reveals this correlation to be located in younger individuals and in women, two separate main effects (interactions were not statistically significant). This does not mean that women use postalveolar /t/ more: in fact, they use it much less than do young men in the community (Sharma, 2011). What Table 3 shows is that women's use of this feature is more sensitive to whether or not they have a very Asian network. By contrast, Gen 2 men have a higher and more consistent use of the form across different age groups, and this usage is not as sensitive to how Asian their network is. Most importantly, this network effect appears late in terms of community history, arising only for women and for the most recent subgroup (younger Gen 2). This finding is discussed later in relation to particular new social indexicalities that have developed in the community.

Table 3: Spearman's correlation coefficients for Asianness of network and postalveolar $/ \mathrm{t} / \mathrm{use}$

\begin{tabular}{ccccccc}
\hline \hline & \multirow{2}{*}{ GEN 1 } & \multicolumn{5}{c}{ GEN 2 } \\
\cline { 3 - 7 } & & TOTAL & younger & older & women & men \\
\hline Spearman's rho & .013 & .645 & .613 & .607 & .667 & .377 \\
Sig. (2-tailed) & .961 & $\mathbf{. 0 0 1 * *}$ & $\mathbf{. 0 2 0 *}$ & .063 & $\mathbf{. 0 1 8 *}$ & .226 \\
\hline \hline
\end{tabular}




\section{Network trait 2: Indianness of network}

Across all three demographic groups, how Indian (born and raised in India) a person's friendship network is showed no significant correlation with their use of postalveolar / $t$ /, so these results are not reported on further.

In contrast to the previous network trait, it is Punjabi use that this network measure correlates with. Table 4 shows that this correlation was again significant overall for Gen 2, but not Gen 1. Once again, this is likely due to, in this case, high network Indianness and high Punjabi use across the board in Gen 1. Within Gen 2, the breakdown according to age and gender in Table 4 shows that it is primarily Gen 2 men for whom a correlation between Indianness of network and Punjabi use is significant. Again, this does not mean that men use more Punjabi; there is no statistically significant gender difference in Punjabi use. Table 4 shows that men's use of Punjabi is influenced by how Indian (transnational) their networks are. Unlike the influence of network on postalveolar / $t /$, here we see little evidence of change over time (age-sensitivity) within this British-born Gen 2 group. I offer an account for this difference in the Discussion.

Table 4: Spearman correlation coefficients for Indianness of network and Punjabi use

\begin{tabular}{rcccccc}
\hline \hline & \multirow{2}{*}{ GEN 1 } & \multicolumn{5}{c}{ GEN 2 } \\
\cline { 3 - 7 } & & TOTAL & younger & older & women & men \\
\hline Spearman's rho & -.063 & .634 & .484 & .377 & .375 & .775 \\
Sig. (2-tailed) & .803 &. $\mathbf{0 0 1}{ }^{* *}$ & .080 & .283 & .229 & $\mathbf{. 0 0 3 * *}$ \\
\hline \hline * $\leq 0.05 . * * p \leq 0.01$. & & & &
\end{tabular}

\section{Network trait 3: Diversity of network}

The initial correlation matrix in Table 2 pointed to a relationship between the third network trait - diversity of network - and the third language feature - accent repertoire. These two are examined together in detail next. The focus here moves from the full set of 42 individuals to the 9 for whom wider accent repertoire data are available.

Table 5 first reports the Diversity Index values and biographical details for these nine individuals, grouped by generation, age, and gender. Network Diversity ranges from 28 named individuals across eight subgroups (Anwar) to 10 named individuals across four subgroups (Simran). Recall that the nature of human social networks is such that Diversity Index values under .5 are unlikely to be attested. The analysis focuses on these nine individuals, as these are the nine with accent repertoire data as well, but the observed trends are maintained across the wider dataset. ${ }^{6}$ Further support for group patterns in Table 5 comes from ethnographic observation of the community, noted in the analysis.

Table 5: Diversity Index values and demographics for nine repertoire cases

\begin{tabular}{lcc}
\hline \hline Name & Gender & Diversity Index \\
\hline GEN 1 (older) & & \\
Mandeep & $\mathrm{M}$ & .76 \\
Nina & $\mathrm{F}$ & .65 \\
GEN 2 (older) & & \\
Anwar & $\mathrm{M}$ & .81 \\
Sharan & $\mathrm{M}$ & .78 \\
$\quad$ Simran & $\mathrm{F}$ & .58 \\
GEN 2 (younger) & & \\
Namrita & $\mathrm{F}$ & .82 \\
Guddi & $\mathrm{F}$ & .79 \\
Anand & $\mathrm{M}$ & .69 \\
Ravinder & $\mathrm{M}$ & .65 \\
\hline \hline
\end{tabular}


Table 5 shows that the Gen 1 and older Gen 2 groups conform to one gender pattern, whereas the younger Gen 2 group reverses that pattern. I describe this gender reversal in some detail here, as it is central to understanding how these network diversity measures relate to the accent repertoires presented shortly.

At the top of Table 5, we see that the Gen 1 man's network is more diverse than that of the Gen 1 woman. The social arrangement of gender roles in the India-born group is typical of many traditional communities, such that the women's lives are somewhat more community-internal and family-based than the men's lives are. This is the basis of the indicative Gen 1 gender difference in Table 5.

What is very striking in Table 5 is that this arrangement continues within the older Gen 2 group, the first age group born locally in Britain. Again, independent social observation of the community supports this. Many older Gen 2 men took over their father's businesses, interacting widely with Indian as well as British business contacts and often becoming political activists during a time of political tension around immigration. By contrast, despite being born in Britain and having local jobs, older Gen 2 women still tended to follow more traditional Asian practices of getting married younger than the men did, completing their education early, and remaining more family- and community-bound.

It is only by the younger Gen 2 group that the community sees a shift to typical Western urban lower-middle-class gender roles. Ethnographic observation, questionnaire responses, and comments by participants in interviews (see Sharma, 2011; Sharma \& Sankaran, 2011) indicated clearly that in this more recent British-born generation, it is younger women who stay in education longer, find employment outside the community, and interface more widely across communities, while younger men tend to be more neighborhood -bound (cf. similar gendered class patterns in Gal [1978], Milroy [1987], and Nichols [1976]). The Diversity Indexes for all four of the younger Gen 2 individuals indicate this systematic reversal of gender roles.

This slow transformation of gender roles, and corresponding networks, is very systematic in Table 5. Even though, like any network metric, the Diversity Index only attends to a few components (the number and relative size of an ego's social worlds) and omits many other details, these structural components may be one significant source of systematic social difference in some communities.

Chambers (1995:125-126) predicted a correspondence of such structural network properties to language use: "in societies where gender roles are sharply differentiated such that one gender has wider social contacts and greater geographical range, the speech of the less circumscribed gender will include more variants of the contiguous social groups."

So how closely does network diversity correspond to accent repertoire? The accent repertoires for these nine individuals are presented in a compact format in Figure 5. As noted earlier, the repertoires track alternation in the use of four salient variables: the gray bars indicate percentage use of Asian variants [t], [e], [o], [1], while the white bars indicate percentage use of British variants $[\mathrm{t}] /[\mathrm{P}]$, [eI], [əv], [t]. ${ }^{7}$ These types of accent repertoire aim to profile individuals' variation at a higher level than individual variants in sociolinguistic interviews. As noted, participants were encouraged to record themselves in a range of settings, preferably with contrasts across home/work contexts and Asian/non-Asian interlocutors. Inevitably, data collected varies across individuals and is not straightforwardly comparable or representative. One way that generalizability is addressed in part is the inclusion of two individuals per demographic subgroup where possible. 


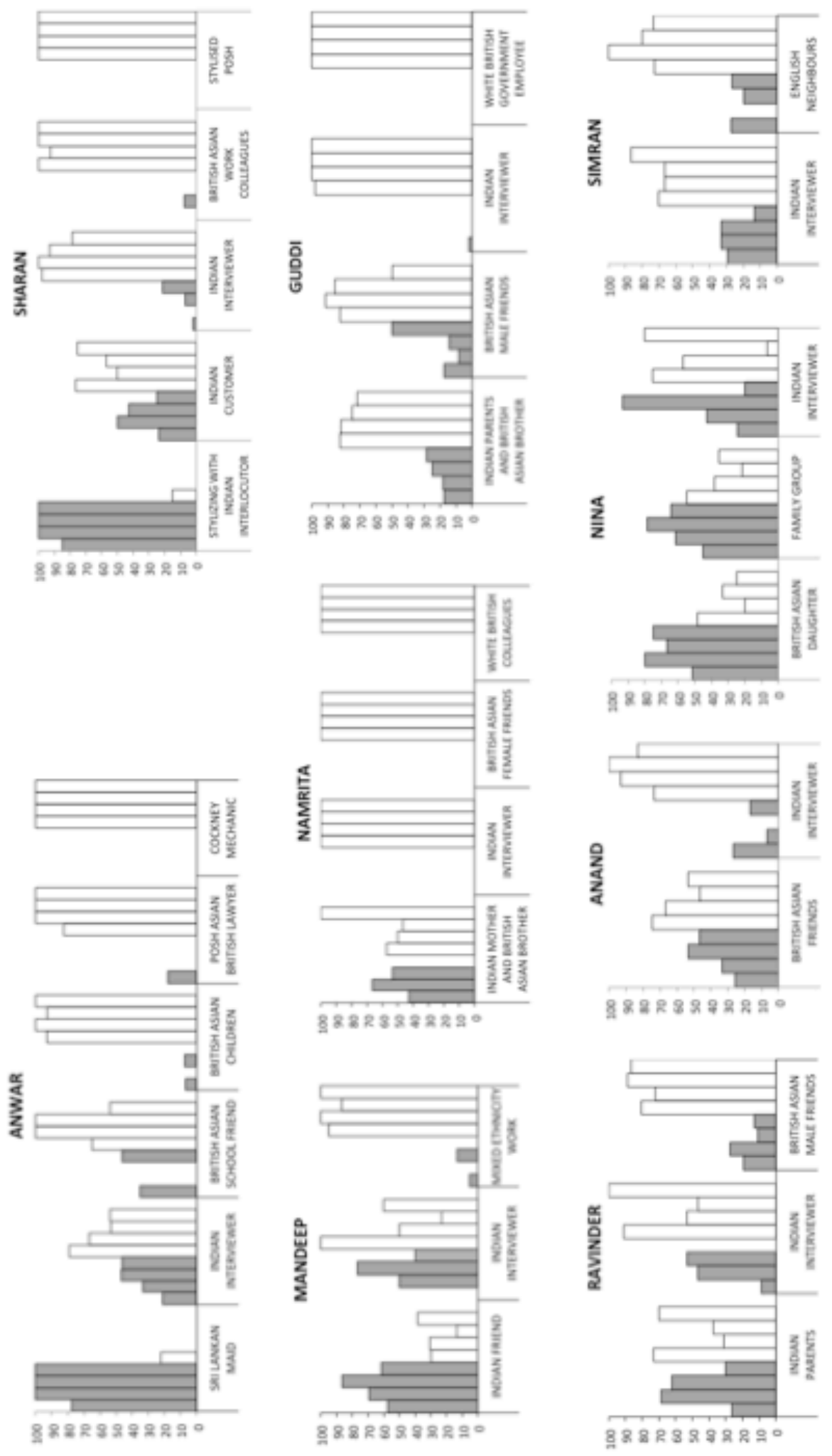

Figure 5: Accent repertoires for nine individuals. Grey bars, in order: Asian variants [t], [e], [o], [1]. White bars, in order: British variants [t], [er], [əひ], [1]. 
The bar charts in Figure 5 show that, despite considerable variability in individual repertoires, it is possible to identify three broad types: (a) repertoires that involve wholesale alternation between complete or pure lects (top row: Anwar, Sharan), (b) repertoires that involve alternation between one pure lect and hybrid mixing (middle row: particularly Namrita and Guddi), and (c) repertoires that involve much slighter shifts in levels of variants, a mix of which is always present across contexts (bottom row: Ravinder, Anand, Nina, Simran).

These groupings correspond very closely to higher Diversity Index scores (top and middle rows) and lower Diversity Index scores (bottom row), respectively. Table 6 attests to this broad correlation. However, it also highlights some limitations of pure quantification at this level.

Table 6: Diversity index values and repertoire details

\begin{tabular}{lcccc}
\hline \hline Name & Demographic & Diversity Index & Repertoire type & \% Accent range \\
\hline Anwar & OlderGen2-M & .81 & differentiated & 94.4 \\
Sharan & OlderGen2-M & .78 & differentiated & 94.3 \\
Mandeep & Gen1-M & .76 & partly differentiated & 64.1 \\
Namrita & YoungerGen2-F & .82 & partly differentiated & 40.7 \\
Guddi & YoungerGen2-F & .79 & partly differentiated & 22.5 \\
Ravinder & YoungerGen2-M & .65 & fused & 29.1 \\
Anand & YoungerGen2-M & .69 & fused & 27.2 \\
Nina & Gen1-F & .65 & fused & 23.1 \\
Simran & OlderGen2-F & .58 & fused & 7.8 \\
\hline \hline
\end{tabular}

$\mathrm{r}=.667, \mathrm{p} \leq .05$

The accent range measure that was used earlier for the initial correlation matrix in Table 2 is included in Table 6 as one way of converting the repertoires in Figure 5 to numerical values for quantitative analysis. Recall that this value represents the maximum observable difference in the combined mean rate of use of four Indian variants across contexts. Actively bilectal individuals such as Anwar and Sharan show rates that approach $100 \%$ because they alternate between whole dialect systems, listed in Table 6 as differentiated. Conversely, an individual with a very limited style range such as Simran has a very low accent range value, and her repertoire is described in Table 6 as fused, indicating the tendency for the forms to recur to some extent across all contexts. The intermediate group, listed as partly differentiated, are individuals whose repertoire does not exhibit fully bilectal alternation between Indian English and British English, as in the differentiated repertoires, but who do alternate between one such pure lect (e.g., British English) and a mixed style. In other words, their hybrid style is circumscribed to a subset of contexts.

It is this intermediate group that illustrates why boiling a full repertoire down to a single numerical value is problematic. Guddi has a relatively low accent range measure, lower than that of her two male peers, but in fact she, and many young British Asian women like her, are notable for their practice of completely turning off their hybrid Asian lect, as we saw in Figure 5.

Younger women's complete elimination of Asian features from their speech in some contexts makes their range much more salient in interaction than that of their younger male peers such as Anand and Ravinder. The latter never "switch off" their Asian style, giving the impression of much less variability despite technically similar ranges. A calculation that attends only to pure ranges, not to qualitative differences in which particular mix of features results, misses this difference in repertoire quality. This qualitative distinction is therefore retained in Table 6 in the column indicating repertoire type. 
Despite these challenges to pure quantification, a strong correspondence can be observed: regardless of generation, gender, and age - which are all implicated in a deep social transformation in the community - an individual's accent repertoire appears to be closely linked to their network diversity.

\section{DISCUSSION}

Figure 6 pulls together the three main network dynamics observed. The effects range from more localized in terms of timescale and affected groups to more general. The first effect - a correlation of ethnicity of network ties with English /t/ pronunciation-arose only in the youngest Gen 2 group, with the additional detail that women are more subject to this influence than men are. The second effect - a correlation of Indianness of ties and Punjabi use - is slightly more general in the community: it applies across the British-born Gen 2 group, particularly men. The final effect - the correlation between diversity of one's network and accent repertoire - although not easy to subject to statistical analysis given the qualitative complexity of the data, points to a level of generality that transcends other sociodemographic specifics.

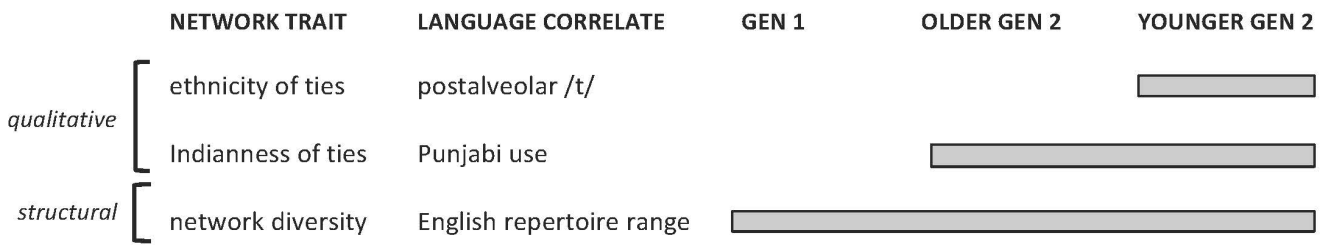

Figure 6: Network effects across scales of time, language structure, and network structure

Networks thus influence language use at different scales, some effects appearing to be more consistent and others more historically contingent. Why do these scalar differences arise? How should they be interpreted, and what generalizations, if any, can be made?

\section{Correlation, causation, and explanation}

The analysis has been careful to discuss the findings in terms of correlation, which cannot be assumed to imply causation, particularly in the case of network effects. A few plausible alternatives are worth noting before the results are interpreted.

A broad challenge to simple causation is potential endogeneity (lack of true independence of predictor variables) in the data. Taking the second result in Figure 6 as an example, we might wish to interpret the maintenance of transnational ties as an independent factor that causes rates of Punjabi use among British Asians to vary. However, two possible types of endogeneity in the data could complicate such a claim. First, causality can be bidirectional, leading to a feedback loop such that maintenance of ties supports Punjabi use, and enhanced Punjabi ability fosters such ties further. Second, variation in one or both variables (Punjabi use and transnational networks) may be driven by a separate confounding variable such as cultural attitude or family history.

This second complication - that network traits may be proxies for less directly observed forces - is particularly important for careful interpretation of results in sociolinguistics more generally. We can take the third result in Figure 6 as another example. Network diversity correlates with accent repertoire diversity, but is network diversity itself the explanatory variable? In principle, it is possible that the driving force for diverse repertoires is not simply network diversity, but the presence of at least one significantly non-Asian social world for an individual, that is, a combination of network diversity and network openness. It is indeed the case that speakers with higher diversity index values in Table 6 also have networks that tend to incorporate 
more non-Asian groups. Disentangling finely covarying network properties remains a methodological challenge for future work.

Bearing these caveats in mind, we can begin to interpret each of the findings in Figure 6.

First, a single account may underlie why postalveolar / $t$ / correlates with ethnicity of network, and why this effect is greater among younger Gen 2 and women. Postalveolar /t/ has undergone phonetic and socioindexical changes over time in this community, developing into one of the main markers of British Asian speech for younger people. The form has gained the status of a stereotype, with participants volunteering it as an example of "Southallian" style. The younger generation distinguish themselves from recent Gen 1 arrivals, sometimes derogatorily termed "freshies," but they continue to use postalveolar /t/, with an altered phonetic profile (Alam \& Stuart-Smith, 2014; Kirkham, 2011; Sharma \& Sankaran, 2011) and integrated with British vernacular phonetic forms. This embeddedness in the British Asian community (as indicated by network Asianness) is negotiated more critically and actively by younger women in the community: Men expressed more uniformly positive stances toward traditional Punjabi culture, whereas young women talked about negotiating the greater social restrictions placed on girls and showed higher rates of work and socializing outside the community (Sharma, 2011). This may account for the gendered and generational constraints on how network Asianness corresponds to a marker of cultural localness, postalveolar $/ \mathrm{t} /$.

The second finding is simpler, namely that across Gen 2, Punjabi use is related to maintenance of transnational ties. This is not surprising given that, in the present data, alters raised in India tend to be Punjabi-dominant. The greater effect for men may be due to the fact that men's transnational activity shows a wide range, depending on whether they go into their father's business, which in this community is often tied to South Asia. It is interesting to note, in passing, a difference to Gal's (1978) findings for Hungarian-German bilinguals in Oberwart. In her study, language choice corresponded to network for the older generation, but younger women actively moved away from Hungarian, regardless of their network. In the present data, the network effect on Punjabi use does not change over time in Gen 2; indeed, there is no statistically significant gender difference in Punjabi use in general in the data. The fact that we do not see women rejecting the community language could point to a degree of vitality of the heritage language, or to less starkly gendered labor conditions, which were argued to be the underlying basis for change in Oberwart. Subtle difference in network dynamics across studies can thus reveal different drivers of language shift.

Finally, the third finding: why do network diversity and accent repertoire correlate closely across demographic subgroups, as was seen in Table 6? At a simple level, it may simply be that accent repertoire reflects the accretion of short- and long-term accommodation, and a diverse network is bound to be instrumental in this outcome. If so, this is an effect that operates at a more fundamental level than the other two more community-specific processes. The final discussion turns to this question of scales of network influence.

\section{The particular and the general}

A multiscale typology of how social networks influence language can facilitate more comparison across communities. Why are some network effects very similar across communities and others not? Under what conditions would the more particular or the more general effects found for the present community be expected to arise in other communities?

First, the particular: Indianness of network was argued to be unrelated to postalveolar /t/ because that form has come to signal a local British Asianness, hence the sensitivity among younger British Asians not to transnational ties but to the local British Asian community (community embeddedness). On the one hand, we might say that this was predictable, due to outer limits on how long transnational ties can exert a direct influence. Incremental shifts from parent to peer norms postmigration, with accompanying focusing of new usage, have been observed in many contexts of migration (Kerswill \& Williams, 2000; Trudgill, 2004). So, a shift 
in influence from transnational network components to locally salient network components (e.g., ethnicity, vernacular culture) is intuitive, particularly in relation to language forms that are known to be becoming markers of the local, such as postalveolar $/ t /$. However, the timescale of such a shift is less predictable. In some communities, the strength of ideology or sustained cultural practices could support lasting translocal influence. Benor (2010) showed that Jewishness of network and frequency of synagogue attendance correlate with Jewish Americans' use of loanwords from Hebrew and Yiddish; one can easily imagine a stable influence of transnational network ties in such a scenario, not gradually weakening as has happened in the community under consideration here. In a more general confirmation of the idea that qualities such as ethnicity need not exert predictable effects, Wassink (2016) showed that ethnic homophily does not uniformly predict greater use of ethnolectal forms across five ethnic groups in Washington state. The influence of certain network qualities on language variation at a given time depends on the community's particular historical and cultural trajectory.

Does the influence of network diversity on repertoire represent a more basic dynamic, one that we can more reliably expect to see in any context? The correspondence of network diversity to repertoire did transcend subgroupings in the data, as did other structural components such as density, openness, and strength of ties in earlier studies. Returning to the original distinction drawn in relation to Figure 1 between qualitative and structural components of networks, we can conclude that, in the present study, the two qualitative ego star measures showed more time- and group-specific effects, whereas the structural ego zone measure showed a more general effect.

Why is this the case? At any given point in its history, a community represents a temporary configuration of social norms, involving heightened cultural salience or influence of specific ways of being, for example, a particular type of ethnic identity, a style of signaling a particular femininity, an oppositional working-class stance, a homeland identity. These qualitative attributes may have particular power over diffusion of certain linguistic forms at that point in time. Which social attributes are involved, how powerful they are, and which linguistic forms do their work, is culturally and historically contingent. This is represented by the examples in the first row in Table 7.

Table 7: Exploratory typology of network effects on language

\begin{tabular}{|c|c|c|c|}
\hline Network property & $\begin{array}{l}\text { Effect on } \\
\text { language }\end{array}$ & Examples & Selected sample studies \\
\hline \multirow[t]{3}{*}{ Network qualities } & \multirow{3}{*}{$\begin{array}{l}\text { culturally and } \\
\text { historically } \\
\text { contingent }\end{array}$} & ethnicity of alters & $\begin{array}{l}\text { present study; Li Wei 1994; Matsumoto } \\
\text { 2010; Cheshire et al. 2008; Wassink } 2016\end{array}$ \\
\hline & & $\begin{array}{l}\text { nationality/language of } \\
\text { alters }\end{array}$ & present study; Stoessel 2002 \\
\hline & & $\begin{array}{l}\text { peasantness, ruralness } \\
\text { of alters }\end{array}$ & Gal 1978; Bortoni-Ricardo 1985 \\
\hline \multirow[t]{3}{*}{ Network structures } & \multirow[t]{3}{*}{ general } & diversity, size & present study; Dodsworth \& Benton fc \\
\hline & & density, openness & $\begin{array}{l}\text { Milroy 1987; Dubois \& Horvath 1998; } \\
\text { Lanza and Svendsen } 2007\end{array}$ \\
\hline & & centrality, peripherality & $\begin{array}{l}\text { Labov 1972, 2001; Trudgill 1974; Paolillo } \\
\text { 1999; Eckert 2000; Fagyal et al. 2010; } \\
\text { Dodsworth \& Benton fc }\end{array}$ \\
\hline
\end{tabular}

By contrast, certain structural properties of networks may be less likely to be subject to culturally or historically specific valuation. It would be unusual for a culture to converge on a culturally specific norm where dense networks do not have a stabilizing effect, but open networks do. Likewise, it would be surprising for a culture to develop a social norm of associating a diverse network with a narrow repertoire and a limited network with a broad repertoire. Core structural 
dimensions of networks, unlike qualitative attributes of networks, may be more impervious to cultural norms, predicting more comparable kinds of influences on language across communities. This is indicated by the examples in the second row in Table 7.

Community-specific variation may nevertheless arise here too. For instance, a community that is steeped in a conflict model of class or race relations (see Rickford, 1986) may place heightened value on strong ties and closed networks. Similarly, repertoire sensitivity to network diversity may be higher for speakers of nonprestige varieties. Speakers of a less prestigious new British Asian variety may expand their repertoires to accommodate a range of social worlds, but speakers of a standard variety might do much less to accommodate to others across contexts. The correlation of diversity and repertoire thus may represent a relatively more consistent effect, but the extent of its applicability across communities and classes requires further research.

\section{CONCLUSION}

Comparing a small set of network metrics has shown that very different pictures of the same data emerge depending on which network dimension and which linguistic form are selected, with network effects also operating at different scales. Qualitative network attributes showed patterns specific to subgroups and accounted for by the historical phase of social change in the community. By contrast, the structural ego zone attribute exerted a more general effect that transcended subgroups and appeared to be more fundamental to social interaction. Both types can give us insight into deeper historical and cultural processes.

Multiscale analysis encourages a more comparative and reflexive methodology, with critical reflection on common measures and practices in the field. The present study has shown the potential for identifying new dimensions of network structure-in this case, diversity of social worlds - that may have special relevance to understanding dynamic language repertoires. In sociology, studies of social networks span micro, meso, and macro scales of analysis. The finding of scalar dynamics here may support a similar sociolinguistic theory of network dynamics, with effects ranging from local and historically contingent to more general and fundamental to interaction. 


\section{ACKNOWLEDGEMENTS}

This work was supported by the Economic and Social Research Council, UK ("Dialect Development and Style in a Diasporic Community," RES-062-23-0604). I am indebted to Ben Rampton, Lavanya Sankaran, audiences at New Ways of Analyzing Variation 42 at the University of Pittsburgh in October 2017 and the International Conference on Language Variation in Europe 7 at Trondheim in June 2013, and two anonymous reviewers for generous and insightful feedback.

\section{NOTES}

1. Nine of the 10 repertoires based on self-recordings are included in this study. The 10th was recorded by a 14-year-old who falls outside of the adult age range examined here, but his low accent repertoire range and low network diversity score conform to the pattern reported here.

2. Information on strength of ties was collected as well but all ties were included in the measure of Indianness of network. An exploratory comparison showed that strong Indian ties were not notably different from all Indian ties in terms of their proportions across individuals.

3. The auditory coding was checked for reliability through blind double-coding by two coders of $5 \%$ of the data, resulting in an inter-rater reliability level of $90 \%$. Postalveolar $/ \mathrm{t} /$ appears in two of the language measures, but its presence in the repertoire data is only one of four elements in the interview setting. Furthermore, aside from Table 2, all the statistical analyses of these two language features are separate.

4. The oldest Gen 2 group has the highest standard deviation in Figures 3 and 4, an indication of their bidialectal and intermediate status in gradual community change.

5. Shapiro-Wilk tests of normality were not significant for five of the six variables $(p>.05$; Indianness: $p=.042$ ), suggesting that this small subset of the data is sufficiently normally distributed for initial parametric testing.

6. The mean Diversity Index values for 22 individuals with complete information on network subgrouping are Gen 1: men .73, women .63; Older Gen 2: men .76, women .65; Younger Gen 2: men .71, women .80.

7. A few values are slightly different to those reported previously (Sharma, 2011) as uncoded variants such as unrealized $/ \mathrm{t} /$ were excluded from the numerator previously but from the denominator here, to allow total values of $100 \%$.

\section{REFERENCES}

Alam, Farhana. (2007). Language and identity in 'Glaswasian' adolescents. M.Litt. dissertation, University of Glasgow.

Alam, Farhana, \& Stuart-Smith, Jane. (2014). Identity, ethnicity and fine phonetic detail: An acoustic phonetic analysis of syllable-initial / $t /$ in Glaswegian girls of Pakistani heritage. In M. Hundt \& D. Sharma (eds.), English in the Indian diaspora. Amsterdam: Benjamins. 2953.

Benor, Sarah Bunin. (2010). Ethnolinguistic repertoire: Shifting the analytic focus in language and ethnicity. Journal of Sociolinguistics 14(2):159-183.

Bergs, Alexander. (2005). Social networks and historical sociolinguistics. Berlin: Mouton de Gruyter.

Blau, Peter. (1977). Inequality and heterogeneity. New York: The Free Press.

Blom, Jan-Petter, \& Gumperz, John J. (1972). Social meaning in linguistic structure: Codeswitching in Norway. In J. J. Gumperz \& D. Hymes (eds.), Directions in sociolinguistics. Oxford: Basil Blackwell. 407-434.

Bloomfield, Leonard. (1933). Language. New York: Henry Holt and Company.

Bortoni-Ricardo, Stella M. (1985). The urbanisation of rural dialect speakers: A sociolinguistic study in Brazil. Cambridge: Cambridge University Press. 
CARF (Campaign against Racism and Fascism). (1981). Southall: The Birth of a black community. London: Institute of Race Relations.

Chambers, Jack. (1995). Sociolinguistic theory. Oxford: Blackwell.

Cheshire, Jenny. (1982). Variation in an English dialect: A sociolinguistic study. Cambridge: Cambridge University Press.

Cheshire, Jenny, Fox, Sue, Kerswill, Paul, \& Torgersen, Eivind. (2008). Ethnicity, friendship network and social practices as the motor of dialect change: Linguistic innovation in London. Sociolinguistica 22:1-23.

de Bot, Kees, \& Stoessel, Saskia. (2002). Introduction: Language change and social networks. International Journal of the Sociology of Language 153:1-7.

Degenne, Alain, \& Forsé, Michel. (1999). Introducing social networks. London: Sage.

Deumert, Ana. (2004). Language standardization and language change: The dynamics of Cape Dutch. Amsterdam: John Benjamins.

Dodsworth, Robin, \& Benton, Richard A. (2017). Social network cohesion and the retreat from Southern vowels in Raleigh. Language in Society 46 (3): 371-405.

Dubois, Sylvie, \& Horvath, Barbara. (1998). Let's tink about dat: Interdental fricatives in Cajun English. Language Variation and Change 10:245-261.

Ealing JSNA (Joint Strategic Needs Assessment). (2010). Ealing JSNA report. Available at: http://www.ealingpct.nhs.uk/Publications/needs-assessment.asp. Accessed November 3, 2010 .

Eckert, Penny. (2000). Linguistic variation as social practice. Oxford: Blackwell.

Fagyal, Zsuzsanna, Swarup, Samarth, Escobar, Anna María, Gasser, Les, \& Lakkaraju, Kiran. (2010). Centers and peripheries: Network roles in language change. Lingua 120:2061-2079.

Gal, Susan. (1978). Peasant men can't get wives: Language change and sex roles in a bilingual community. Language in Society 7:1-16.

Herbert, Joanna. (2009). Oral histories of the Ugandan Asians in Britain: Gendered identities in the diaspora. Contemporary South Asia 17(1):21-32.

Heselwood, Barry, \& McChrystal, Louise. (2000). Gender, accent featured and voicing in Panjabi-English bilingual children. Leeds Working Papers in Linguistics and Phonetics 8:45-70.

Hoffman, Michol, \& Walker, James. (2010). Ethnolects and the city: Ethnic orientation and linguistic variation in Toronto English. Language Variation and Change 22:37-67.

Hulsen, Madeleine, de Bot, Kees, \& Weltens, Bert. (2002). Between two worlds: Social networks, language shift and language processing in three generations of Dutch migrants in New Zealand. International Journal of Sociology of Language 153:27-52.

Kerswill, Paul, \& Williams, Ann. (2000). Creating a new town koine: Children and language change in Milton Keynes. Language in Society 29:65-115.

Kirkham, Sam. (2011). The acoustics of coronal stops in British Asian English. In W.-S. Lee \& E. Zee (eds.), Proceedings of the ICPhS XVII), 17-21 August 2011, Hong Kong, China. Hong Kong: City University of Hong Kong. 1102-1105.

Labov, William. (1972). Language in the inner city: Studies in the Black English vernacular. Philadelphia: University of Pennsylvania Press. (2001). Principles of linguistic change. Vol. 2. Social factors. Malden: Blackwell.

Lambert, Kirsten, Alam, Farhana, \& Stuart-Smith, Jane. (2007). Investigating British Asian accents: Studies from Glasgow. In J. Trouvain \& W. J. Barry (eds.), Proceedings of the 16th International Congress of Phonetic Sciences: ICPhS XVI, 6-10 August 2007, , Saarbrücken, Germany. Saarbrücken: Universität des Saarlandes. 1509-1511.

Lanza, Elizabeth, \& Svendsen, Bente Ailin. (2007). Tell me who your friends are and I might be able to tell you what language(s) you speak: Social network analysis, multiligualism, and identity. International Journal of Bilingualism 11(3):275-300.

Li, Wei. (1994). Three generations, two languages, one family: Language choice and language 
shift in a Chinese community in Britain. Philadelphia: Multilingual Matters.

Lippi-Green, Rosina. (1989). Social network integration and language change in progress in an alpine rural village. Language in Society 18:213-34.

Matsumoto, Kazuko. (2010). The role of social networks in the post-colonial multilingual island of Palau: Mechanisms of language maintenance and shift. Multilingua 29:133-165.

Meads, R. J. (1983). Southall 830-1982. London: Merlin.

Meyerhoff, Miriam, \& Schleef, Erik. (2012). Variation, contact and social indexicality in the acquisition of (ing) by teenage migrants. Journal of Sociolinguistics 16(3):398-416.

Milardo, Robert M. (1988). Families and social networks: An overview of theory and methodology. In R. M. Milardo (ed.), Families and social networks. Newbury Park: Sage. 13-47.

Milroy, Lesley. (1987). Language and social networks. 2nd ed. Oxford: Wiley-Blackwell.

Milroy, James \& Milroy, Lesley. (1978). Belfast: Change and variation in an urban vernacular. In P. Trudgill (ed.), Sociolinguistic patterns in British English. London: Arnold. 19-36.

Moore, Emma. (2006). 'You tell all the stories': Using narrative to explore hierarchy within a Community of Practice. Journal of Sociolinguistics 10(5):611-640.

Newman, Michael. (2010). Focusing, implicational scaling, and the dialect status of New York Latino English. Journal of Sociolinguistics 14(2):207-239.

Nichols, Patricia. (1976). Black women in the rural South: Conservative and innovative. In B. L. Dubois \& I. Crouch (eds.), The sociology of the languages of American Women. San Antonio: Trinity University. 45-54.

Oates, Jonathan. (2002). Southall and Hanwell. London: The History Press Ltd.

Paolillo, John. (1999). The virtual speech community: Social network and language variation on IRC. Journal of Computer Mediated Communication 4(4). doi: 10.1111/j.10836101.1999.tb00109.x. Available at: http://onlinelibrary.wiley.com/doi/10.1111/j.10836101.1999.tb00109.x/full. Accessed 20 November 2016.

Rickford, John. (1986). The need for new approaches to social class analysis in sociolinguistics. Language and Communication 6:215-221.

Sharma, Devyani. (2011). Style repertoire and social change in British Asian English. Journal of Sociolinguistics 15(4):464-492.

Sharma, Devyani, \& Sankaran, Lavanya. (2011). Cognitive and social factors in dialect shift: Gradual change in London Asian speech. Language Variation and Change 23:399-428.

Simpson, Edward H. (1949). Measurement of diversity. Nature 163:688.

Smith, L. Ripley. (2002). The social architecture of communicative competence: A methodology for social-network research in sociolinguistics. International Journal of the Sociology of Language 153:133-160.

Stoessel, Saskia. (2002). Investigating the role of social networks in language maintenance and shift. International Journal of the Sociology of Language 153:93-131.

Trudgill, Peter. (1974). The social differentiation of English in Norwich. Cambridge: Cambridge University Press. (2004). New-dialect formation: The inevitability of colonial Englishes. Edinburgh: Edinburgh University Press.

Wassink, Alicia Beckford. (2016). The Social Networks of Minority Ethnicity Group Members in Washington State. Paper presented at the 45th New Ways of Analyzing Variation conference, Seattle, Washington, 3-6 November, 2016.

Wetherell, Charles. (1998). Historical social network analysis. International Review of Social History 43:125-144.

Wong, Amy. (2010). New York City English and second generation Chinese Americans. English Today 26(3):3-11. 